\title{
A Cross-Country Comparison of Attitudes toward Humanoid Robots in Germany, the US, and India
}

\author{
Nadine Homburg \\ Ludwig Maximilian University Munich \\ nstockhomburg@yahoo.de
}

\author{
Moritz Merkle \\ Technische Universität Darmstadt \\ moritzmerkle@web.de
}

\begin{abstract}
So far, researchers know very little about what people actually expect from humanoid robots during a human-robot interaction. Therefore, this study surveyed 610 non-experts from Germany (133), the US (174), and India (303) and asked them to rate the following attributes regarding humanoid robots: empathy, expertise, reliability, and trust. This paper develops hypotheses, connecting robot attributes to the four cultural dimensions suggested by Hofstede individualism, masculinity versus femininity, power distance, and uncertainty avoidance. The results show, that India rates all the attributes the highest, and that Germany and the US rate all aspects rather similarly with the largest difference regarding reliability.
\end{abstract}

\section{Introduction}

Humanoid robots are becoming more popular and are used more and more as service robots in humanrobot interactions. Therefore, we chose the customer interaction with a service robot as exemplary situation although our results refer to human-robot interaction in general. Ivanov, Webster, and Berezina [22] give an overview of where service robots such as the humanoid robot Pepper are already applied today. Their examples include restaurants, hotels, theme and amusement parks, airports, and other public spaces. Their paper is a great example for the fact that facing humanoid robots will soon be unavoidable.

When looking at current research, there are many studies that focus on the acceptance of humanoid robots. However, there is very little known about the expectations towards robots, which becomes more important with the increased application of humanoid service robots. In this paper, we surveyed what participants expect from humanoid robots in terms of expertise, the extent to which they trust a robot, how reliable they expect a robot to be, and how much empathy they expect from a robot. We chose these aspects as they were identified as important for human service employees by prior service literature [18].

For future research, these results are important to take into consideration, as this study gives an overview about what users expect from humanoid robots. This might have an impact on the results of experimental studies, which will be further examined in the discussion.

Furthermore, this study provides more detailed insights about specific cultures and their connection to technology. This is important for future research depending on which country the study will be conducted in.

Moreover, this research cannot only be used for future research including humanoid robots and service encounters but for general human-robot interactions. For example, the attribution of trust is also important in terms of health care. With the decrease in the number of health care professionals [34], it is important to figure out, whether robots might be able to solve this problem. This is especially important in terms of trust. Broadbent, Stafford, and MacDonald [4] for example, give an overview on "literature about human responses to healthcare robots". This study could help future research in this area, especially when conducting research in specific countries. For example, when conducting robotic experiments in one of the countries surveyed, the results of this study could be used to explain further results in this area.

There are already some studies about the acceptance of or attitude toward different robots in different countries, which are visualized in the literature review (Table 1). In these studies, acceptance and attitudes towards robots were the main outcome variables examined based on different factors. The literature review indicates that the US, European, and Asian countries account for a substantial part of overall robotic research. In terms of the countries considered in this study, literature already provides first insights into the impact of cultural differences as described subsequently.

$\mathrm{Li}, \mathrm{Rau}$, and $\mathrm{Li}$ [24] found that Germany scored the lowest on trust compared to China and Korea. 


\begin{tabular}{|c|c|c|c|}
\hline $\begin{array}{l}\text { Author/s } \\
\text { (year) }\end{array}$ & $\begin{array}{l}\text { Countries } \\
\text { (Number of } \\
\text { participants) }\end{array}$ & Examined variables & Major findings \\
\hline $\begin{array}{l}\text { Bartneck et } \\
\text { al. (2005, } \\
2006)\end{array}$ & $\begin{array}{l}\text { China (44), } \\
\text { Germany (109), } \\
\text { Japan (135), } \\
\text { Mexico (21), } \\
\text { Netherlands (41), } \\
\text { UK (58), } \\
\text { USA (59) }\end{array}$ & $\begin{array}{l}\text { Attitudes towards interaction } \\
\text { with robots, attitudes } \\
\text { towards } \\
\text { social influence of robots, } \\
\text { attitudes towards emotions } \\
\text { in interaction with robots }\end{array}$ & $\begin{array}{l}\text { Interaction: Mexico highest, USA } \\
\text { lowest; } \\
\text { Social influence: China highest, } \\
\text { USA lowest; } \\
\text { Emotions: Japan highest, Mexico } \\
\text { lowest }\end{array}$ \\
\hline $\begin{array}{l}\text { Broadbent, } \\
\text { Stafford, and } \\
\text { MacDonald } \\
\text { (2009) }\end{array}$ & $\begin{array}{l}\text { USA }(N / A), \\
\text { Japan }(N / A), \\
\text { France }(N / A), \\
\text { Germany }(N / A), \\
\text { Korea }(N / A)\end{array}$ & $\begin{array}{l}\text { Acceptance and attitudes of } \\
\text { robots in the healthcare } \\
\text { sector }\end{array}$ & $\begin{array}{l}\text { French more accepting than } \\
\text { Germans; Japanese thought that } \\
\text { humanoid robots are more human } \\
\text { like; different roles for Japanese } \\
\text { and Americans }\end{array}$ \\
\hline $\begin{array}{l}\text { Evers et al. } \\
(2008)\end{array}$ & $\begin{array}{l}\text { USA (31), China } \\
\text { (27) }\end{array}$ & $\begin{array}{l}\text { Acceptance of choices } \\
\text { (comparing humans and } \\
\text { robots) }\end{array}$ & $\begin{array}{l}\text { US: higher trust with both; } \\
\text { China: more comfortable with both }\end{array}$ \\
\hline $\begin{array}{l}\text { Green, } \\
\text { MacDorman, } \\
\text { Ho, and } \\
\text { Vasudevan } \\
\text { (2008) }\end{array}$ & $\begin{array}{l}\text { USA (479), } \\
\text { Japan (237) }\end{array}$ & $\begin{array}{l}\text { Attitude towards robots } \\
\text { depending on experience }\end{array}$ & $\begin{array}{l}\text { Both countries prefer people over } \\
\text { robots (USA more than Japan) }\end{array}$ \\
\hline Kaplan (2004) & $\begin{array}{l}\text { Japan, Western } \\
\text { Countries }\end{array}$ & $\begin{array}{l}\text { Review of Japanese and } \\
\text { western culture influencing } \\
\text { myths and novels regarding } \\
\text { artificial beings }\end{array}$ & - \\
\hline $\begin{array}{l}\text { Li, Rau, and } \\
\text { Li (2010) }\end{array}$ & $\begin{array}{l}\text { China (36), } \\
\text { Korea (36), } \\
\text { Germany (36) }\end{array}$ & $\begin{array}{l}\text { Robot appearance and task } \\
\text { as factors, on robot's } \\
\text { likeability. } \\
\text { Engagement with, trust in } \\
\text { and satisfaction with the } \\
\text { robot. }\end{array}$ & $\begin{array}{l}\text { German: lowest on all } 4 \text { scales } \\
\text { Chinese and Korean results rather } \\
\text { similar, Korea lower trust }\end{array}$ \\
\hline $\begin{array}{l}\text { Ouwehand } \\
\text { (2017) }\end{array}$ & $\begin{array}{l}\text { Netherlands, } \\
\text { Japan: } \\
\text { comparative } \\
\text { case analysis }\end{array}$ & $\begin{array}{l}\text { The extent to which elderly } \\
\text { are willing to accept robots } \\
\text { into their lives }\end{array}$ & $\begin{array}{l}\text { Thesis, that culture has an } \\
\text { influence on the acceptance of } \\
\text { social assistive robots }\end{array}$ \\
\hline $\begin{array}{l}\text { Rau, Li, and } \\
\text { Li (2009) }\end{array}$ & $\begin{array}{l}\text { China (16), } \\
\text { Germany (16) }\end{array}$ & $\begin{array}{l}\text { Effects of communication } \\
\text { styles and cultures on } \\
\text { accepting recommendations } \\
\text { from a robot }\end{array}$ & $\begin{array}{l}\text { Chinese participants would rather } \\
\text { accept recommendations than } \\
\text { German participants }\end{array}$ \\
\hline $\begin{array}{l}\text { Salem, } \\
\text { Ziadee, and } \\
\text { Sakr (2014) }\end{array}$ & $\begin{array}{l}\text { English (44) and } \\
\text { Arabic native } \\
\text { speakers (48) }\end{array}$ & $\begin{array}{l}\text { Acceptance and } \\
\text { anthropomorphization of } \\
\text { humanoid robots }\end{array}$ & $\begin{array}{l}\text { Arabic native speakers more } \\
\text { positive toward humanoid robots }\end{array}$ \\
\hline
\end{tabular}


Furthermore, $\mathrm{Rau}, \mathrm{Li}$, and $\mathrm{Li}$ [32] found that more people in China would rather accept a recommendation from a robot than would people in Germany.

In the US for example, MacDorman, Vasudevan, and Ho [25], found that people from the US generally preferred people over robots. Evers et al. [8] conducted an experimental study and found that US participants reported higher trust in robots and were more compliant with robotic assistants than Chinese participants.

To our knowledge, no study about the acceptance of robots in India has been conducted so far. The findings from this literature review will be further discussed in the hypotheses section.

This study was conducted in Germany, the US, and India to take the different cultural aspects of these countries into account. Especially in India, a country with increasing economic power, there could be major potential for the use of humanoid robots. This aspect will be expanded in the discussion when taking the results and potential use of robots into account.

\section{Cultural Concept by Hofstede}

To be able to compare the culture of each country, the Cultural Concept of Hofstede [12][14] was chosen. The concept describes the culture of countries through the use four dimensions: Power distance, Individualism, Masculinity versus Femininity, and Uncertainty avoidance. Hofstede [16] rated countries on a scale of 1-100 for each of these dimensions. The ratings for each country can be found at: https://www.hofstedeinsights.com. Next, we will define the four dimensions and build our hypotheses.

Power distance. “ ... that is, the extent to which the less powerful members of organizations and institutions (such as the family) accept and expect that power is distributed unequally.” [15, p.62]

Uncertainty avoidance. “... deals with a society's tolerance for ambiguity. It indicates to what extent a culture programs its members to feel either uncomfortable or comfortable in unstructured situations." [15, p.62]

Individualism. “ ... versus its opposite, collectivism, refers to the degree to which individuals are integrated into groups." [15, p.63]

Masculinity. “ ... versus its opposite, femininity, refers to the distribution of emotional roles between the sexes, another fundamental problem for any society to which a range of solutions are found." $[15, \mathrm{p} .63]$
Especially interesting when looking at the rating for each country (Figure 1) are the differences in individualism in all three countries as well as the rather similar rating of masculinity with the maximum difference being 10 .

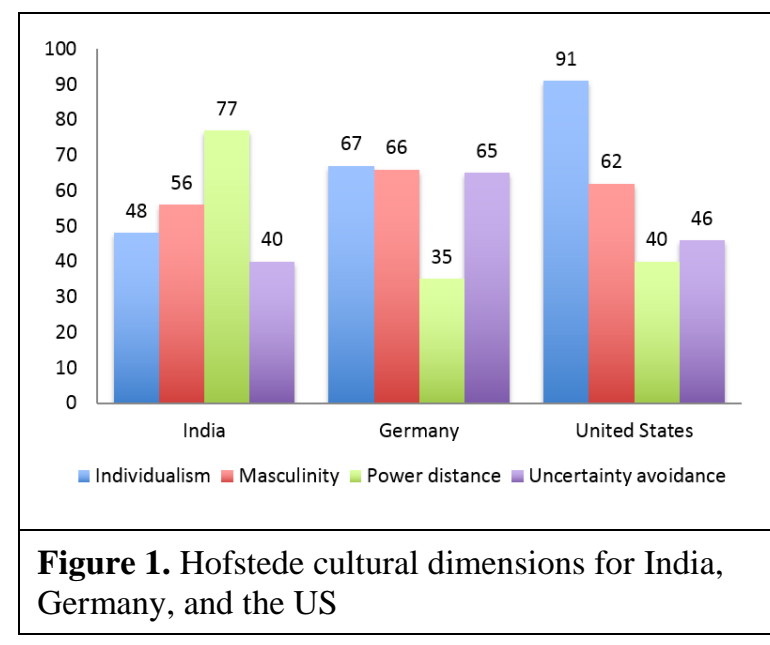

\section{Hypotheses}

In our study we looked for mainly four variables: Empathy, Reliability, Expertise, Trust. After referring to the definition of each, we will introduce our hypotheses, based on the Cultural Concept by Hofstede and on prior studies as shown in the literature review.

\subsection{Empathy}

Empathy is "the capacity to clearly project an interest in others and to obtain and reflect a reasonable complete and accurate sense of another's thoughts, feelings, and experiences" [3]. Prior research already studied the gender differences regarding empathy. Christov-Moore et al. [5], for example show that there are "behavioral and neural differences in affective empathy between males and females." Females tend to be more empathic than males [11]. Transferred to Hofstede's cultural dimension of masculinity versus femininity of a society, we assume that cultures with a higher level of masculinity (and therefore low level of femininity) attribute lower empathy to a robot.

H1: India (lower masculinity) has higher expectations toward a robot's empathy during a human-robot interaction than Germany and the US. 


\subsection{Reliability}

Reliability "is defined as the extent to which a salesperson assures that promises made to customers are met [30] and that customer instructions are precisely followed" [18, p.402]. The higher the reliability of a service, the lower is the uncertainty about the reactions and behaviors of the service representative.

Therefore, we suggest that reliability is connected to uncertainty avoidance, as low uncertainty avoidance means that a culture is more open toward humanoid robots. They might question the reliability less than a culture of high uncertainty avoidance.

H2: Germany (highest uncertainty avoidance) has a lower score on reliability towards the robot during a human-robot interaction than the US and India (lower uncertainty avoidance).

\subsection{Expertise}

Expertise "is defined as the presence of knowledge and ability to fulfill a task" [28][3, p.394].

Cultures with a high level of uncertainty avoidance prefer to be on the safe side and expect guaranteed expertise. We suggest that these cultures with high uncertainty avoidance are more likely to question the expertise of new things that they have little experience with. Therefore, they would be rather skeptical when it comes to humanoid robots. This would be a similar phenomenon to the one described in the context of reliability (see 3.2). Comparable to the previous section, we assume that countries with high uncertainty avoidance would associate less expertise with the robot.

H3: Germany (highest uncertainty avoidance) has a lower score on expertise towards the robot during a human-robot interaction than the US and India (lower uncertainty avoidance).

\subsection{Trust}

Definition: "most researchers agree that trust is a personal characteristic that refers to "a willingness to rely on an exchange partner in whom one has confidence" [26, p.82].

We assume that trust is significantly based on uncertainty avoidance. Cultures that are generally more open towards new things will have an easier way of trusting them. Therefore, we assume that the higher the uncertainty avoidance the lower the trust and the lower the individualism the higher the trust. Furthermore, prior studies like $\mathrm{Li}, \mathrm{Rau}$, and $\mathrm{Li}$ [24], which is also mentioned in our literature review, already examined the trust in robots compared to humans in Germany, Korea, and China. In this study, Germany scored the lowest on trust. This would support our hypotheses, as Germany with the highest uncertainty avoidance would have to score the lowest on trust.

H4a: Germany (highest uncertainty avoidance) has a lower score on trust than the US and India (lower uncertainty avoidance).

Finally, the higher the femininity (and the lower the masculinity) the higher the trust.

H4b: India (lowest masculinity) has the highest score on trust towards the robot during a human-robot interaction.

\section{Method}

\subsection{Data collection}

To address our research objectives we conducted a cross-country survey study with data from the US, from Germany and from India. Data from the US and from Germany were collected with paper pencil questionnaires at public places such as shopping malls and train stations. For the Indian data, we relied on Amazon's MTurk to find participants for our study. We further asked the participants to provide their city of residence within the questionnaire to make sure that the MTurk respondents were from India.

Recent studies raised quality concerns about data gathered via MTurk [21]. Therefore we included two control questions such as "please click on disagree if you read this question carefully" to check whether the participants were reading the questions carefully and giving conscientious answers [10]. 256 out of 866 filled questionnaires had to be excluded from this study due to wrong answers to our control questions. However, many studies already relied on Amazon "MTurk as apotential mechanism for conducting research in psychology and other social sciences" [2, p. 5], verifying demographic declarations [31], validating psychometric properties of MTurk responses [2] and were able to replicate classic paper pencil findings with MTurk [19][35].

The questionnaire showed a picture of the Pepper robot from Softbank Corp, to give participants an example of a service robot. This type of robot was chosen, as Pepper is already in widespread use in the service context [33]. After the participants watched the picture, they were asked to provide demographic data and rate humanoid robots in the categories empathy, expertise, reliability and trust. 
The constructs are measured by multiple items that were adapted from service literature [18] to fit for a service robot. Empathy is assessed with the use of six items based on scales suggested in extant research [6][17][29]. The expertise of the robot is measured on an eight-item scale that was developed based on the scales of [1], [7] and [18]. The constructs reliability [28] and trust [7] were also adapted to fit for a robot. All these items were rated on a seven-point Likert sale from 'strongly disagree' to 'strongly agree'.

\subsection{Characteristics of the sample}

As current research provides evidence, that demographics as age [9] and gender [23] affect the acceptance of robots, we strived to reach a representative average population sample. Our sample of 303 participants includes 338 men and 272 women whose average age was 38.2 years ranging from the age of 7 until 95 years. Moreover, the sample represents a range of occupations and a variety of different experience levels with robots.

\subsection{Findings}

First we describe the findings for the examined countries in detail. Subsequently we compare the three countries with one another.

4.3.1. Findings for the three countries. Table 2 shows the mean differences among the robot attributes of the 174 US participants. The confidence in the expertise and the reliability of the robot scores significantly higher than for empathy and trust. The attributes for reliability and expertise are on the same level.

\begin{tabular}{|c|c|c|c|}
\hline & 1 & 2 & 3 \\
\hline 1_Empathy1 & -- & & \\
\hline 2_Expertise ${ }^{1}$ & $1.18^{*}$ & -- & \\
\hline 3_Reliability 1 & $1.16^{*}$ & -.02 & -- \\
\hline 4_Trust ${ }^{1}$ & $.66^{*}$ & $-.52^{*}$ & $-.50^{*}$ \\
\hline \multicolumn{4}{|c|}{${ }^{1}$ Measured on a 7-point likert scale; $p<.05$} \\
\hline
\end{tabular}

Table 3 shows the mean differences among the robot attributes for the 133 German participants taking part in our study. German participants report high attributions of expertise whereas the scores for trust $\left(\Delta \mathrm{M}=-.67^{*}\right)$ and empathy $\left(\Delta \mathrm{M}=-1.76^{*}\right)$ are significantly lower.
Robots reached high scores for all of the categories from our 303 Indian participants, although the attribute for the robots' empathy scores slightly lower than the other attributes. The mean differences among the robot attributes in India are shown in Table 4.

\begin{tabular}{|c|c|c|c|}
\hline & 1 & 2 & 3 \\
\hline 1_Empathy1 & -- & & \\
\hline 2_Expertise ${ }^{1}$ & $1.76^{*}$ & -- & \\
\hline 3_Reliability ${ }^{1}$ & $1.52^{*}$ & $-.24^{*}$ & -- \\
\hline 4_Trust ${ }^{1}$ & $1.09^{*}$ & $-.67^{*}$ & $-.43^{*}$ \\
\hline
\end{tabular}

Table 4. Mean differences among the robot attributes in India

\begin{tabular}{|l|l|l|l|}
\hline & \multicolumn{1}{|c|}{1} & \multicolumn{1}{|c|}{2} & \multicolumn{1}{c|}{3} \\
\hline 1_Empathy & -- & & \\
\hline 2_Expertise ${ }^{1}$ & $.26^{*}$ & -- & \\
\hline 3_Reliability ${ }^{1}$ & $.28^{*}$ & .02 & -- \\
\hline 4_Trust ${ }^{1}$ & $.26^{*}$ & .00 & -.02 \\
\hline${ }^{1}$ Measured on a 7-point likert scale; $p<.05$ \\
\hline
\end{tabular}

4.3.2. Comparison of the countries. Comparing the responses of the Indian participants with those of US participants and German participants there is a clear trend: Indians attribute robots significantly $(\mathrm{p}<.05)$ higher values for empathy, expertise, reliability and trust (see Table 5).

Participants from the US and Germany rate the robot on the same level regarding its expertise. German participants rate the robot slightly lower with respect to reliability and trust, whereas the biggest gap occurs regarding the evaluation of the robot's empathy. US participants attribute the robot significantly higher values regarding empathy $(\mathrm{M}=3.98)$ compared to the German participants $(M=3.39)$.

Regarding empathy, expertise, reliability, and trust, the results from Germany and the US are rather similar while the results from India are higher in all four sections. (Table 5) The biggest difference occurs regarding empathy. While Indian respondents assume that robots have a rather high degree of empathy, 
German and US respondents are not of the opinion that robots have a high empathy.

All three countries rated the robot high on expertise with India being a little higher than Germany and the US. Regarding reliability, Germany rated the robot the lowest and India the highest. However, all three countries think of the robot as rather reliable. While India shows high trust in robots, Germany and the US rated trust lower, with Germany trusting robots the least.

These results clearly show that India as an increasing economic power generally rates robots higher that countries like Germany and the US. Therefore, there is a very high potential for robots in the Indian market, due to high trust and openness.

The results also point out, that conducting robot studies in India is not the same as conducting a study in one of the other countries surveyed. hypothesis it rates the lowest on reliability $(\mathrm{M}=4.91)$ from these three countries.

5.1.3. Expertise. For expertise, H3 was also supported. However, the difference between the ratings is rather small $(\Delta \mathrm{M}=.33)$ while the difference between the ratings in uncertainty avoidance is rather large $(\Delta=25)$ (especially between India and Germany). We therefore suggest that even though uncertainty avoidance is a factor, it influences the rating of expertise rather little.

5.1.4. Trust. In Hypotheses $\mathrm{H} 4 \mathrm{a}$ and $\mathrm{H} 4 \mathrm{~b}$ we proposed that uncertainty avoidance and masculinity have a negative effect on trust in the robot. Both hypotheses were supported, as Germany with the highest uncertainty avoidance (65) shows the lowest score of

\begin{tabular}{|c|c|c|c|c|c|c|}
\hline & US $^{1}$ & GER $^{2}$ & $\mathrm{IND}^{3}$ & $\begin{array}{c}\text { Mean } \\
\text { difference } \\
\text { US-GER }\end{array}$ & $\begin{array}{c}\text { Mean } \\
\text { difference } \\
\text { US-IND }\end{array}$ & $\begin{array}{c}\text { Mean } \\
\text { difference } \\
\text { GER-IND }\end{array}$ \\
\hline Empathy ${ }^{4}$ & $3.98(1.48)$ & $3.39(1.27)$ & $5.22(1.12)$ & $.59^{*}$ & $-1.24^{*}$ & $-1.83^{*}$ \\
\hline Expertise $^{4}$ & $5.16(1.16)$ & $5.15(.92)$ & $5.48(.83)$ & .01 & $-.32^{*}$ & $-.33^{*}$ \\
\hline Reliability ${ }^{4}$ & $5.14(1.57)$ & $4.91(1.13)$ & $5.50(.93)$ & .23 & $-.36^{*}$ & $-.59^{*}$ \\
\hline Trust $^{4}$ & 4.64 (1.33) & $4.48(1.06)$ & $5.48(.88)$ & .16 & $-.84^{*}$ & $-1.00^{*}$ \\
\hline
\end{tabular}

One can suggest that experiments in India can be conducted more easily due to high trust while in Germany they can be rather difficult in comparison. This could also be due to factors like "the German fear".

\subsection{Connection to Hofstede}

5.1.1. Empathy. Regarding empathy, H1 is supported. Compared to the other surveyed countries, India has the lowest masculinity (56) and the highest rate for empathy $(\mathrm{M}=5.22)$. In addition, Germany, with the highest masculinity (66), rates lowest on empathy $(\mathrm{M}=3.39)$. However, because the difference in masculinity between India, Germany, and the US is rather small compared to their difference in empathy, we assume that there are other major factors influencing empathy.

5.1.2. Reliability. Regarding reliability, $\mathrm{H} 2$ was supported. Germany rates overall high, in spite of a high score in uncertainty avoidance (65) and in line with our trust in the robot $(\mathrm{M}=4.48)$ and India with the lowest masculinity $(56)$ has the significantly $(\mathrm{p}<.05)$ highest trust $(\mathrm{M}=5.48)$ in robots.

Overall, all of our hypotheses were supported. However, there are several surprising aspects, for example, to which extend the aspects were rated in spite of the Hofstede dimensions.

\section{Discussion}

\subsection{Research implications}

The starting point was relating Hofstede's Cultural Concept to the aspects surveyed about humanoid robots through our hypotheses. The major findings were that India scored the highest on all four aspects, while the US and Germany rate the aspects lower and rather similar.

This study is one of several studies (Table 1) to research robot acceptance in different cultures. To our knowledge, this is the second research that applies 
Hofstede's Cultural Concept with roots in management to the field of robotics. There was already a thesis by Anouk Ouwehand [27] to compare the acceptance for social assertive robots in the Netherlands compared to Japan. However, this paper used a comparative case analysis.

This research reveals that it also provides valuable insights for the understanding of cultural differences in the perception of robots. So far, extant literature essentially relies on plausibility considerations. Future research could rely more intensively on managerial culture approaches, such as Hofstede [13], GLOBE [20], or Trompenaars' approach [36].

The results of this study are especially important for future research regarding all kinds of humanoid robot studies done in these countries. Especially interesting are the results for India, as it shows the potential for using robots.

Furthermore, this study shows that studies done in one country are not necessarily representative for another country. Here, from what can be seen from the results of this study, Germany and the US are rather comparable, while India is not. When surveying these aspects, the results show that the cultural concept by Hofstede can be used as a starting point for hypotheses. As robots develop it can be assumed that more aspects will be surveyed in the future about robot acceptance as robots become for skilled for example. Therefore, more aspects can be correlated to Hofstede.

Furthermore, it would be interesting to look at the developments in these aspects in different countries over the years, as robots advance. When researching these aspects in more countries, researchers could also find a general approach for robot or technology acceptance in a country. With this general approach, a new Hofstede dimension could be added, as there are six so far.

However, limitations of this research include applying these results to non-humanoid robots, as participants were specifically asked to rate a humanoid robot and were give a picture of the Pepper.

\subsection{Managerial implications}

The results of this study are especially important for future research regarding all kinds of humanoid robots studies done in these countries. Especially interesting are the results for India, as it shows the potential for using robots. As India rates all aspects the highest from all three countries, humanoid robots could be tasked with many more things than in Germany or the US.

For example, India has high trust in robots. Therefore, humanoid robots in India could be used for tasks where higher trust is needed, e.g., elder care. However, in Germany (with a lower trust in robot), one could suggest using humanoid robots as regular service robots. Here, humanoid robots in elder care might be less accepted due to a lower level of trust. This is for example also something Broadbent, Stafford, and MacDonald [4], from our literature review studied and they found that Germany is less accepting of robots in health care than for example a country like France.

\subsection{Limitations and further research}

This study examines how cultural dimensions influence robot attributes. However, the attribution of robots is not only defined by the cultural background. Correlations indicate that prior experience with robots increases attribute levels of empathy $(\mathrm{r}(610)=.26$, $\mathrm{p}<.001)$ and trust $(\mathrm{r}(610)=.12, \mathrm{p}<.001)$ with the robot. The participants' age decreases the attribute of empathy $(\mathrm{r}(610)=-.64, \mathrm{p}<.001)$ and trust $(\mathrm{r}(610)=-.35, \mathrm{p}<.001)$ with the robot. Future research could find out more about how different factors such as age affect these attributes in different countries.

Furthermore, the original theory of Hofstede proposed the four dimensions applied in this study. By now, two new dimensions have been added to the concept. Future research could examine the effects of the new Hofstede dimensions long-term orientation and indulgence versus self-restraint. For this paper however, we chose to use only the original dimensions for out hypotheses and for the explanation of the results. As more research is done on the new dimensions, future research could also connect these results to the two new dimensions.

Even though the participants were asked to rate the attributes during a service interaction, the attributes are not limited to service interactions with humanoid robots. However, the results of this research are limited to humanoid robots and cannot be implied for nonhumanoid robots, due to lager differences between the robot types.

\section{Acknowledgements}

The authors would like to thank the Förderverein für marktorientierte Unternehmensfïhrung for the grateful support.

Additionally we would like to thank Ruth StockHomburg and Daniel Homburg for helping us collecting paper questionnaires.

\section{References}

[1] D. N. Behrman and W. D. Perreault, "Measuring the Performance of Industrial Salespersons", Journal of Business Research, vol. 10, 1982, pp. 355-370. 
[2] M. Buhrmester, T. Kwang, and S. D. Gosling, “Amazon's Mechanical Turk: A new source of cheap, yet high-quality, data?", Perspectives on Psychological Science, vol. 6, 2011, pp. 3-5.

[3] V. D. Bush, G. M. Rose, F. Gilbert, and T. N. Ingram, "Managing Culturally Diverse Buyer-Seller Relationships: The Role of Intercultural Disposition and Adaptive Selling in Developing Intercultural Communication Competence", Journal of the Academy of Marketing Science, vol. 29:4, 2001, pp. 391-404.

[4] E. Broadbent, R. Stafford, and B. MacDonald, "Acceptance of Healthcare Robots for the Older Population: Review and Future Directions", International Journal of Social Robotics, vol. 1:4, 2009, pp. 319-330.

[5] L. Christov-Moore, E. A. Simpson, G. Coudé, K. Grigaityte, M. Iacoboni, and P. F. Ferrari, "Empathy: Gender Effects in Brain and Behavior", Neuroscience \& Biobehavioral Reviews, vol. 46, 2014, pp. 604-627.

[6] M. H. Davis, "Measuring Individual Differences in Empathy: Evidence for a Multidimensional Approach", Journal of Personality and Social Psychology, vol. 44, 1983, pp. 113-126.

[7] P. M. Doney and J. P. Cannon, "An Examination of the Nature of Trust in Buyer-Seller Relationships", Journal of Marketing, vol. 61, 1997, pp. 35-51.

[8] V. Evers, H. Maldonado, T. Brodecki, and P. Hinds, "Relational vs. Group Self-Construal: Untangling the Role of National Culture in HRI", IEEE International Conference on Human-Robot Interaction, 2008, pp. 255-262.

[9] N. Ezer, A. D. Fisk, and W. A. Rogers, "Attitudinal and Intentional Acceptance of Domestic Robots by Younger and Older Adults", International Conference on Universal Access in Human-Computer Interaction, 2009, pp. 39-48.

[10] T. Finin, W. Murnane, A. Karandikar, N. Keller, J. Martineau, and M. Dredze, "Annotating Named Entities in Twitter Data With Crowdsourcing", Proceedings of the NAACL HLT Workshop on Creating Speech and Language Data with Amazon's Mechanical Turk, 2010, pp. 80-88.

[11] M. L. Hoffman, "Sex Differences in Empathy and Related Behaviors", Psychological Bulletin, vol. 84:4, 1977, pp. 712722.

[12] G. Hofstede, "Culture and Organizations", International Studies of Management \& Organization, vol. 10:4, 1980, pp. $15-41$.

[13] G. Hofstede, "Culture's Consequences: International Differences in Work-Related Values", vol. 5, 1984, Sage Publications.
[14] G. Hofstede, "Culture's Consequences: Comparing Values, Behaviors, Institutions and Organizations Across Nations", vol. 2, 2003, Sage Publications.

[15] G. Hofstede, and R. R. McCrae, "Personality and Culture Revisited: Linking Traits and Dimensions of Culture", CrossCultural Research, vol. 38:1, 2004, pp. 52-88.

[16] G. Hofstede and G. J. Hofstede, "Cultures and Organizations Software of the Mind", 2005, New York, McGraw-Hill Publishing.

[17] J. Hogan and R. Hogan, "How to Measure Service Orientation”, Journal of Applied Psychology, vol. 69, 1984, pp. 167-173.

[18] C. Homburg, and R. M. Stock, "Exploring the Conditions Under Which Salesperson Work Satisfaction Can Lead to Customer Satisfaction", Psychology \& Marketing, vol. 22:5, 2005, pp. 393-420.

[19] J. J. Horton, D. G. Rand, and R. J. Zeckhauser, "The online laboratory: Conducting experiments in a real labor market", Experimental Economics, vol.14, 2011, pp. 399 425 .

[20] R. J. House, P. J. Hanges, M. Javidan, P. W. Dorfman, and V. Gupta, "Culture, Leadership, and Organizations: The GLOBE Study of 62 Societies”, 2004, Sage Publications.

[21] R. G. Ipeirotis, F. Provost, and J. Wang, "Quality Management on Amazon Mechanical Turk", Proceedings of the ACM SIGKDD Workshop on Human Computation, 2010, pp. 64-67.

[22] S. Ivanov, C. Webster, and K. Berezina, "Adoption of Robots and Service Automation by Tourism and Hospitality Companies", INVTUR Conference, 2017, pp. 17-19, Aveiro, Portugal.

[23] I. H. Kuo, J. M. Rabindran, E. Broadbent, Y. I. Lee, N. Kerse, R. M. Q. Stafford, and B. A. MacDonald, "Age and Gender Factors in User Acceptance of Healthcare Robots", IEEE International Symposium on Robot and Human Interactive Communication, 2009, pp. 214-219.

[24] D. Li, P. P. Rau, and Y. Li, "A Cross-Cultural Study: Effect of Robot Appearance and Task", International Journal of Social Robotics, vol. 2:2, 2010, pp. 175-186.

[25] K. F. MacDorman, S. K. Vasudevan, and C. C. Ho, "Does Japan Really Have Robot Mania? Comparing Attitudes by Implicit and Explicit Measures", AI \& Society, vol. 23:4, 2009, pp. 485-510.

[26] C. Moorman, R. Deshpande, and G. Zaltman, „Factors Affecting Trust in Market Research Relationships", Journal of Marketing, vol. 57:1, 1993, pp. 81-101.

[27] A. N. Ouwehand, "The Role of Culture in the Acceptance of Elderly towards 'Social Assertive Robots: How do Cultural 
Factors Influence the Acceptance of Elderly People towards Social Assertive Robotics in the Netherlands and Japan?", Bachelor's Thesis at University of Twente, 2017.

[28] A. Parasuraman, V. A. Zeithaml, and L. L. Berry, "SERVQUAL: A Multiple-Item Scale for Measuring Consumer Perceptions of Service Quality", Journal of Retailing, vol. 64, 1988, pp. 12-39.

[29] A. Parasuraman, V. A. Zeithaml, and L. L. Berry, "Refinement and Reassessment of the SERVQUAL Scale", Journal of Retailing, vol. 67, 1991, pp. 421-450.

[30] A. Parasuraman, V. A. Zeithaml, and L. L. Berry, "Reassessment of Expectations as a Comparison Standard in Measuring Service Quality: Implications for Further Research", Journal of Marketing, vol. 58:1, 1994, pp. 111-124.

[31] D. G. Rand, "The promise of Mechanical Turk: How online labor markets can help theorists run behavioral experiments", Journal of Theoretical Biology, vol. 299:4, 2012, pp. 172-179.
[32] P. P. Rau, Y. Li, and D. Li, "Effects of Communication Style and Culture on Ability to Accept Recommendations From Robots", Computers in Human Behavior, vol. 25:2, 2009 , pp. 587-595.

[33] Softbank, Website, 2018, https://www.softbankrobotics.com, accessed on 30.05.2018.

[34] N. Super, "Who Will be There to Care? The Growing Gap Between Caregiver Supply and Demand", National Health Policy Forum, George Washington University, 2002.

[35] S. Suri, S., and D. J. Watts, "Cooperation and contagion in webbased, networked public goods experiments", PLoS One, vol. 6:3, 2011.

[36] F. Trompenaars and P. Woolliams, "A New Framework for Managing Change Across Cultures", Journal of Change Management, vol. 3:4, 2002, pp. 361-375. 


\section{Appendix}

\begin{tabular}{|c|c|}
\hline \multicolumn{2}{|r|}{ Table 6. Measures and Items (Robot attributes) } \\
\hline Construct & Items \\
\hline \multicolumn{2}{|c|}{ Empathy $(\alpha=.91)$} \\
\hline \multicolumn{2}{|c|}{ In my opinion, a service robot is typically able to... } \\
\hline & ... have a high level of empathy with respect to my need as a customer. \\
\hline & ... have no difficulty determine my needs. \\
\hline & ... trying to determine my needs by adopting my perspective. \\
\hline & ... find it easy to adopt my perspective as a customer. \\
\hline & ... adapt its interactions to my needs in different situations. \\
\hline \multicolumn{2}{|c|}{ Expertise $(\alpha=.88)$} \\
\hline \multicolumn{2}{|c|}{ In my opinion, a service robot is typically able to... } \\
\hline & ... find an adequate solution if I have individual requirements. \\
\hline & ... offer me solutions which are very well thought through. \\
\hline & $\begin{array}{l}\text {... have the expertise that is needed to understand the information provided by } \\
\text { me as a customer. }\end{array}$ \\
\hline & ... be very well organized. \\
\hline & ... know its company's product/service range very well. \\
\hline & ... be very knowledgeable. \\
\hline & ... hardly make mistakes. \\
\hline & $\begin{array}{l}\text {... be knowledgeable about the newest developments (new products, new } \\
\text { technologies, etc.). }\end{array}$ \\
\hline \multicolumn{2}{|c|}{ Reliability $(\alpha=.71)$} \\
\hline \multicolumn{2}{|c|}{ In my opinion, a service robot is typically able to... } \\
\hline & ... be relied upon. \\
\hline & ... be sure to promise deadlines are met. \\
\hline & ... be sure that my instructions are precisely followed. \\
\hline & ... be very reliable. \\
\hline \multicolumn{2}{|c|}{ Trust $(\alpha=.89)$} \\
\hline \multicolumn{2}{|c|}{ In my opinion, if I was dealing with a service robot, I would ... } \\
\hline & ... trust this robot to a large extend. \\
\hline & ... be convinced that this service robot would keep its promises made to me. \\
\hline & ... if I read this question right, I will mark agree for this line. \\
\hline & ... believe that this service robot would be fair and honest with me. \\
\hline & ... believe that the information provided by this service robot would be correct. \\
\hline & $\begin{array}{l}\ldots \text { be convinced that this service robot would deliver the products/services } \\
\text { correctly. }\end{array}$ \\
\hline & ... be convinced that this service robot would keep my best interests in mind. \\
\hline
\end{tabular}

